\title{
EDUCAÇÃO INFANTIL E AMPLIAÇÃO DA OBRIGATORIEDADE ESCOLAR: IMPLICAÇÕES PARA O DESENVOLVIMENTO CULTURAL DA CRIANÇA
}

Maria Nazaré da Cruz ${ }^{1}$

RESUMO: Este texto discute algumas decorrências das políticas de ampliação da obrigatoriedade escolar para a educaçáo infantil e suas relaçôes com o ensino fundamental, visando a problematizar implicaçóes dessas políticas para o desenvolvimento cultural da criança, a partir da psicologia histórico-cultural. Argumenta que a extensão da escolaridade obrigatória tem consequências importantes para os modos de viver a infância e, se náo for acompanhada das condiçóes necessárias ao aprimoramento da qualidade da educaçáo, acaba por negar possibilidades de desenvolvimento às crianças brasileiras.

Palavras-chave: Educação infantil. Obrigatoriedade escolar. Desenvolvimento infantil. Psicologia histórico-cultural.

\section{Early childhood education and extension of compulsory schooling: repercussions for the cultural development of the child}

ABSTRACT: The present article discusses some consequences of policies of expansion of compulsory schooling for early childhood education and their connections with elementary school. It problematizes the repercussions of these policies for the children's

${ }^{1}$ Universidade Metodista de Piracicaba, Programa de Pós-graduação em Educação, Faculdade de Ciências Humanas - Piracicaba (SP), Brasil. E-mail: nazare.mncruz@gmail.com DOI: 10.1590/CC0101-32622017173587 
cultural development, based on historical-cultural psychology. It argues that the extension of compulsory schooling has significant impact on the ways of experiencing childhood and if it is not accompanied by necessary conditions to improve the education quality, it can deny development possibilities to Brazilian children.

Keywords: Early childhood education. Compulsory schooling. Child development. Historical-cultural psychology.

\section{INTRODUÇÃO}

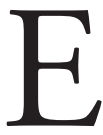

ste texto tem origem na preocupação com as decorrências, para a educação infantil, da implantaçẫo do ensino fundamental de nove anos e da posterior extensão da obrigatoriedade escolar para as crianças de pré-escola. Considerando a ampliação da obrigatoriedade como uma importante evolução no que tange ao direito à educação, particularmente quando "uma parcela significativa das crianças pobres só consegue ter acesso à escola a partir da faixa etária obrigatória” (ALVES; PINTO, 2011, p. 131), entendemos que os modos pelos quais tal ampliação se efetiva são fundamentais para garantir a qualidade da educação ofertada às crianças brasileiras.

Nosso objetivo é refletir sobre algumas implicações das políticas de ampliação da obrigatoriedade escolar em curso para os processos de desenvolvimento cultural e de formação da criança, a partir da perspectiva da psicologia histórico-cultural. Considerando que, para Vigotski (1996, p. 264), "a realidade social é a verdadeira fonte de desenvolvimento" e que a escola tem um papel fundamental nesse processo, argumentamos que a formulação e implantação dessas políticas — que interferem nas condiçóes de vida e de escolarização das crianças - têm consequências importantes para o modo como elas vivem a infância e para o processo de sua formação.

Nessa direção, problematizamos, a partir de pesquisas do campo da educação, as decorrências das políticas de ampliação da obrigatoriedade escolar para a educaçáo infantil, focando particularmente suas relaçóes com o ensino fundamental. Em seguida, apresentamos as concepçóes da perspectiva histórico-cultural sobre o desenvolvimento infantil e suas relaçóes com o processo de escolarização para, ao final, 
tecermos considerações sobre as implicações das políticas discutidas para o processo de formação e desenvolvimento cultural da criança.

\section{AS RELAÇÕES ENTRE EDUCAÇÃO INFANTIL E ENSINO FUNDAMENTAL NO CONTEXTO DA AMPLIAÇÃO DA OBRIGATORIEDADE ESCOLAR}

Há quase 30 anos a Constituição Federal estabelecia, pela primeira vez na história do país, o direito à educação das crianças menores de 6 anos, tendo sido seguida pela Lei de Diretrizes e Bases da Educação Nacional (LDBEN), em 1996, que definiu a educação infantil como primeira etapa da educação básica. Se, desde então, os direitos à educação e ao cuidado das crianças pequenas ficaram determinados, sua implementação tem sido constantemente ameaçada "por duas forças poderosas: a escolarização precoce da criança de 0 a 6 anos e da pré-escola; a assistencialização das creches ou da oferta para as crianças pobres” (ROSEMBERG, 2007, p. 8).

Nas últimas décadas, um conjunto de normas e documentos foi produzido (CORREA, 2011b) com vistas a orientar e regular o processo de organização da educação infantil e a garantir sua qualidade e os direitos das crianças (por exemplo: BRASIL, 1998; 1999; 2005; 2006c). Entretanto, mesmo com esse progresso da legislação e com avanços no atendimento às crianças, as políticas públicas de educação infantil ainda permanecem precárias, uma vez que, como analisa Correa (2011a), os investimentos financeiros nessa etapa da educação básica têm sido insuficientes. Com a instituição do Fundo de Manutenção e Desenvolvimento do Ensino Fundamental e de Valorização do Magistério (Fundef), em 1996, a educação infantil perdeu recursos para o ensino fundamental. Dez anos depois, com o Fundo de Manutenção e Desenvolvimento da Educação Básica e de Valorização dos Profissionais da Educação (Fundeb), embora tenha sido incluída na distribuição dos recursos, esses ainda permaneceram insuficientes para "as necessidades específicas do trabalho com crianças na faixa de 0 a 6 anos" (CORREA, 2011b, p. 27).

É na conjuntura de diminuição dos recursos destinados à educação infantil provocada pelo Fundef que a ampliação do ensino fundamental de oito para nove anos começa a ser delineada, a partir 
do processo de municipalização da educação (ARELARO; JACOMINI; KLEIN, 2011), tendo sido implementada em uma situaçáo na qual o atendimento às crianças de seis anos na pré-escola, apesar de se constituir direito dessa população há quase duas décadas, ainda não estava universalizado. Para Arelaro, Jacomini e Klein (2011, p. 38), a existência de crianças de seis anos fora da escola produziu "um aparente consenso" de que a ampliação do ensino fundamental para nove anos "asseguraria a essas crianças a efetivação do seu direito à educação".

Nesse contexto, o foco das normativas e documentos que orientaram a implantação do ensino fundamental de nove anos (como BRASIL, 2004; 2006b; 2007; 2009a,b) recai sobre o processo de integração das crianças de seis anos ao ensino fundamental, sem implicar nenhuma outra mudança substancial nesse nível da educação básica. Questóes relativas à brincadeira e ao lúdico, à alfabetização e ao letramento tornam-se centrais nas discussóes e nas orientaçóes oficiais sobre a inserção das crianças de seis anos no primeiro ano do ensino fundamental.

Tais questóes também estão presentes em pesquisas de mestrado e doutorado, desenvolvidas na última década, sobre as articulaçóes entre a educação infantil e o ensino fundamental de nove anos, particularmente focadas na transição das crianças de uma etapa a outra (CHULEK, 2012; LIMA, 2013; MARCONDES, 2012; MARTINATI, 2012; MASCIOLI, 2012; NEVES, 2010; NOGUEIRA, 2011; RABINOVICH, 2012). Essas pesquisas indicam que à ampliação do ensino fundamental não correspondeu maior integração entre essas duas etapas da educação básica, já que não há nenhum tipo de preparo das crianças de educação infantil para o ingresso no ensino fundamental, como também não há nenhuma preocupação das escolas de ensino fundamental em adaptar-se às crianças que recebem, seja em termos de espaço físico, materiais ou currículo, ou ainda em termos de interesse e reconhecimento referentes à vida anterior da criança na pré-escola. Para Martinati (2012, p. 209), ao ingressar na educação infantil, "é como se nascesse uma nova criança, que tem que se ajustar à nova realidade".

Essas pesquisas também destacam que a restrição da brincadeira, a presença acentuada de práticas de controle corporal e de silenciamento das crianças, bem como a ênfase em atividades mecânicas de alfabetização são características das escolas de ensino fundamental estudadas. Nos contextos investigados por Neves (2010), Nogueira (2011) e Marcondes 
(2012), isso denota um descompasso em relação à educação infantil, já que em seu cotidiano a brincadeira é central e as práticas "revelaram uma proposta sensível às manifestaçóes e aos anseios das crianças, comprometida com a formação de leitores e autores competentes através da interação com situações reais de leitura e escrita” (NOGUEIRA, 2011, p. 272).

Outros trabalhos, no entanto, sublinham o objetivo preparatório da pré-escola (LIMA, 2013), na qual a aprendizagem da leitura e da escrita é privilegiada, em detrimento das brincadeiras e das interaçóes; e indicam que, tanto quanto o ensino fundamental, a educação infantil não tem sido capaz de desenvolver práticas pedagógicas que respeitem o desenvolvimento infantil, os direitos e necessidades das crianças e que considerem suas expectativas sobre a escola e o processo de escolarizaçáo (MASCIOLI, 2012). Nessa direção, Martinati (2012) assinala que, no contexto por ela investigado, embora o brincar apresente na educação infantil uma centralidade que não possui no ensino fundamental, o faz de conta é tratado de forma ambígua pela professora na pré-escola, que reconhece sua importância, mas não atua intencionalmente em relação a ele.

O quadro delineado por esse conjunto de pesquisas sobre a transição das crianças de seis anos da educação infantil para o ensino fundamental sugere a persistência de algumas das contradiçóes, apontadas em levantamento de Campos, Füllgraf e Wiggers (2006) sobre a qualidade da educação infantil em estudos divulgados entre 1996 e 2003, momento anterior à implementação do ensino fundamental de nove anos. As autoras apontam que importantes mudanças foram produzidas na educação infantil durante esse período de transição pós-LDBEN, no que diz respeito à formação dos profissionais de educação infantil, às propostas pedagógicas, às condiçôes de funcionamento e às práticas educativas. Contraditoriamente, no entanto, essas mudanças conviviam/convivem com modelos de atendimento para creches e pré-escolas historicamente arraigados em tradiçóes assistencialistas e/ou em tendências preparatórias e antecipatórias $^{1}$ do ensino fundamental. No caso da pré-escola, no período estudado, encontrava-se predominantemente rotinas rígidas pautadas por atividades formais, mecânicas e repetitivas, baseadas em um modelo escolar limitado.

Essas contradiçóes parecem ser decorrentes, entre outras coisas, da identidade pouco consolidada da educação infantil e da falta de clareza sobre "a posição da primeira infância na sociedade" (ROSEMBERG, 
2007 , p. 8), o que também tem determinado, em grande medida, os modos de relação com o ensino fundamental.

Quando a consideramos [a primeira infância] como uma etapa preparatória para a verdadeira vida, uma etapa de curta duração, concebemos a EI [educaçáo infantil] como preparatória à verdadeira vida escolar, que se inicia com o ensino compulsório, com as verdadeiras aprendizagens, da leitura, da escrita, dos cálculos. Nesta ótica, esquecemos que a criança pequena está vivendo sua humanidade hoje, sua cidadania hoje, ao mesmo tempo em que constitui as bases para o futuro (ROSEMBERG, 2007, p. 9).

Nesse sentido, as recentes reorganizações da educação básica, com a implantação do ensino fundamental de nove anos pela Lei $\mathrm{n}^{\circ}$ 11.274/2006 (BRASIL, 2006a) e, em seguida, a obrigatoriedade da pré-escola instituída pela Lei no $12.796 / 2013$ (BRASIL, 2013), podem fortalecer a tendência a práticas caracterizadas como antecipatórias ou preparatórias do ensino fundamental, além de colocar em risco a expansão do atendimento às crianças de zero a três anos na educação infantil.

No que tange à política de ampliação da obrigatoriedade escolar dos 4 aos 17 anos, em 2011, Alves e Pinto já indicavam que sua eficácia dependeria da expansão de cerca de 4 milhóes de matrículas, das quais 39,6\% deveriam ser de crianças de 4 e 5 anos. Essa expansão exigiria um crescimento de 9,5\% no orçamento do Fundeb, para que as novas matrículas não representassem "uma reduçấo no já reduzido valor por aluno proporcionado pelo atual mecanismo de financiamento" (ALVES; PINTO, 2011, p. 146). Os autores destacaram também que, se essa ampliação não garantisse uma oferta de educação com qualidade para todos, poderia ocasionar uma inclusáo apenas quantitativa, que não produziria os efeitos esperados para os indivíduos e para a sociedade.

Para a educação infantil, existem — inerentes ao risco da expansão das matrículas sem a qualidade necessária — os perigos de exclusão do cuidado, com a diminuiçấo de vagas em tempo integral; de cisão entre creche e pré-escola; e de privatização e precarização do atendimento em creches (VIEIRA, 2011; KRAMER; NUNES; CORSINO, 2011). Mais uma vez, no contexto de avanços importantes para a educação infantil — como o da ampliação do 
acesso das crianças de quatro e cinco anos à pré-escola — ela se vê ameaçada, de um lado, pela assistencializaçáo da creche, com abertura de possibilidades "de alternativas de atendimento não formais, em espaços domésticos ou não, inadequados aos critérios educacionais, com pessoas sem formação e qualificação" (VIEIRA, 2011, p. 247); e, de outro, pela antecipação da escolaridade das crianças de pré-escola, nos moldes do ensino fundamental.

Nesse contexto, é quase impossível deixar de lembrar o mito de Sísifo, evocado por Rosemberg (2007) para referir-se à instabilidade da educação infantil e

[à] ameaça constante de rebaixamento para soluçóes milagrosas e de ocasiáo, o que dificulta a construção contínua de sua identidade, de competências brasileiras para a instalação de um modelo brasileiro sólido de instituiçáo educacional pública para crianças pequenas com qualidade e equidade (ROSEMBERG, 2007, p.8).

As descontinuidades e a reiteração permanente de velhas ameaças têm dificultado a consolidação de um projeto de educação infantil que possa de fato proporcionar melhores condiçóes de vida e de escolarização às crianças brasileiras, o que nos leva a indagar sobre implicaçóes dessa conjuntura para os modos como as nossas crianças têm vivido sua infância e para o seu processo de formação e desenvolvimento cultural.

\section{ESCOLA E DESENVOLVIMENTO DA CRIANÇA NA PERSPECTIVA HISTÓRICO-CULTURAL}

Quando falamos da infância numa perspectiva histórico-cultural, referimo-nos a uma "infância histórica" (ELKONIN, 1996, p. 395). Mudanças históricas no lugar que a criança ocupa como participante da sociedade transformam todo o sistema de relaçóes entre as crianças e dessas com os adultos, o que implica alteraçóes importantes nos seus processos de formação e de desenvolvimento cultural. Condiçóes de vida, processos educativos e instituiçóes sociais são, nesse contexto, constitutivos da formação da criança e, numa sociedade desigual como 
a nossa, acabam por produzir possibilidades de formação também desiguais. Nessa medida, compreender que a formulação e a implantaçáo de políticas públicas para a infância, como as que discutimos nesse texto, apresentam decorrências fundamentais para o desenvolvimento cultural das crianças, assinala nossa responsabilidade histórica em relação às possibilidades de formação que lhes são oferecidas ou negadas.

Em Psicologia da Arte, Vigotski diz que "basta olhar para uma criança e se perceberá que nela há muito mais possibilidades de vida do que aquelas que se realizam" (1999, p. 312). No contexto em que foi enunciado, esse excerto assume um conjunto de significaçóes que não serão exploradas neste texto. $\mathrm{O}$ que nos interessa aqui é destacar que as possibilidades de vida, a que se refere Vigotski, não remetem a qualquer tipo de potencialidade orgânica ou metafísica, mas à natureza histórico-cultural do desenvolvimento humano, à ideia de que nos constituímos humanos não apenas como resultado de nossas próprias experiências diretas, mas fundamentalmente pela apropriação da experiência cultural acumulada pela humanidade.

O desenvolvimento é compreendido como processo de elaboração de formas histórico-sociais de comportamento (VYGOTSKI, 1995, p. 305) e, sendo assim, a história do desenvolvimento da criança está profundamente entrelaçada à sua história de escolarização. Na perspectiva histórico-cultural, a escola teria como objetivo a ampliação máxima dos âmbitos da experiência pessoal da criança, que é sempre limitada. Dito de outro modo, ela visaria a "estabelecer contato entre o psiquismo da criança e as esferas mais amplas da experiência social já acumulada", de modo a "incluir a criança na rede mais ampla possível da vida” (VIGOTSKI, 2001, p. 351).

Portanto, se durante muito tempo consideramos que a aprendizagem da escrita ou da aritmética apenas dependiam do desenvolvimento anterior de determinadas capacidades e habilidades da criança, as formulaçóes de Vigotski possibilitam pensar que a aprendizagem desses conteúdos transforma e reorganiza o próprio desenvolvimento. Ao apropriar-se deles, a criança náo apenas penetra na cultura, assimilando-a e se enriquecendo com ela, mas "a própria cultura reelabora em profundidade a composição natural de sua conduta e dá uma orientação completamente nova a todo curso de seu desenvolvimento" (VYGOTSKI, 1995, p. 305).

Para compreender o processo de desenvolvimento da criança, é necessário, antes de tudo, levar em conta o que Vigotski (1995, p. 141) 
denomina "peculiaridades positivas do comportamento da criança", ou seja, considerar não aquilo que lhe falta em comparação com o homem adulto, mas as qualidades e a riqueza de possibilidades de seu comportamento atual. Isso só é possível se modificarmos radicalmente nossa concepção sobre o desenvolvimento infantil, percebendo:

Que se trata de um complexo processo dialético que se distingue por uma complicada periodicidade, pela desproporçáo no desenvolvimento das diferentes funçôes, pelas metamorfoses ou transformação qualitativa de umas formas em outras, um entrelaçamento complexo de processos evolutivos e involutivos, pelo complexo cruzamento de fatores internos e externos, por um complexo processo de superação de dificuldades e de adaptaçáo (VYGOTSKI, 1995, p. 141).

O desenvolvimento infantil não é um processo padronizado e biologicamente preestabelecido, mas se origina do confronto entre a criança e seu meio, sendo engendrado num movimento criativo da criança para adaptar-se ao mundo. Para Vigotski, não há uma forma final predeterminada que orienta o desenvolvimento da criança desde seus primeiros passos; ao contrário, esse se faz na relação que ela estabelece com seu meio social. Vigotski denomina essa relação de "situação social do desenvolvimento" (VYGOTSKI, 1996, p. 264) e a considera:

o ponto de partida para todas as mudanças dinâmicas que se produzem no desenvolvimento durante o período de cada idade. Determina plenamente e por inteiro as formas e a trajetória que permitem à criança adquirir novas propriedades da personalidade, já que a realidade social é a verdadeira fonte de desenvolvimento, a possibilidade de que o social se transforme em individual (VYGOTSKI, 1996, p. 264).

Sendo assim, a situação social de desenvolvimento numa determinada idade é o que pauta o modo de existência social da criança e que dará ensejo a novas formaçóes psíquicas que, por sua vez, reestruturam a 
sua consciência ${ }^{2}$. Dito de outro modo, as reestruturaçóes da consciência da criança são resultado de suas formas de existência social. As novas formaçóes que se produzem num dado momento do desenvolvimento, ao modificarem a consciência da criança, transformam completamente sua relação com a realidade social e consigo mesma, destruindo a situação social de desenvolvimento anterior e dando origem a uma nova (VYGOTSKI, 1996).

Nessa abordagem, portanto, o meio não é apenas situação ou circunstância em que o desenvolvimento se processa, mas é fonte desse. Todavia, o meio não encerra em si qualidades e características que, por si próprias, promoveriam o desenvolvimento da criança. Conforme Pino (2010, p. 747) sintetiza, "a influência do meio no desenvolvimento da criança dependerá da própria dinâmica do desenvolvimento”. Esse é um princípio importante para compreender o papel da escola no desenvolvimento da criança, já que:

[o] processo educativo, ao colocar a criança perante novos fins e novas tarefas, ao colocar novas perguntas e procurar os meios necessários, conduz o desenvolvimento. Por outro lado, a própria educaçáo depende do desenvolvimento da criança, da sua idade e das suas características individuais (KOSTIUK, 1991, p. 33).

Desse modo, é necessário admitir que o processo de escolarização da criança pode, conforme sua organização, ao invés de promover o desenvolvimento cultural da criança, limitá-lo, se não levar em consideração as relaçóes entre o que a criança é e as suas possibilidades de desenvolvimento em curso.

Desse ponto de vista, as relaçóes que se estabelecem entre educação infantil e ensino fundamental, se quisermos promover a formação de nossas crianças, tornando disponíveis amplas possibilidades para o seu desenvolvimento cultural, não podem ser reduzidas à mera continuidade como se, para a criança, se tratasse de pura somatória de aquisiçóes; nem tampouco à simples ruptura, que desconsidera o vivido e elaborado em períodos anteriores. Também não podem ser compreendidas apenas como antecipação e preparação, uma vez que antecipar, na educação infantil, tarefas e conteúdos próprios do ensino fundamental não significa necessariamente preparar as 
crianças, do mesmo modo que não se promove desenvolvimento negando aquilo que a criança é e o seu modo atual de existência social.

Numa perspectiva histórico-cultural, a força motriz do desenvolvimento, como nos lembra Kostiuk (1991, p. 35), reside nas contradições entre as novas exigências feitas à criança e sua satisfação, entre os problemas e objetivos que se colocam para ela e as suas condiçóes de desenvolvimento, entre as suas possibilidades subjetivas e as relaçóes objetivas que estabelece com o mundo social. Para ele:

[n]ão pode haver desenvolvimento da personalidade sem que estejam presentes as exigências da sociedade; mas estas exigências só são realistas quando se criam no decurso do desenvolvimento da criança as capacidades para as satisfazer (KOSTIUK, 1991, p. 33).

Do contrário, o que se produz é fracasso. A educação fracassa quando atribui à própria criança e à sua atividade espontânea o papel de condutora do processo educacional, focando tão somente no que a criança é, e não lhe faz novas exigências, nem lhe apresenta novos conhecimentos, novos interesses, novas sensaçóes, novas formas de agir e de pensar, ampliando suas possibilidades de ser. Mas também fracassa se, ao fazê-lo, não considera as relaçóes da criança com o mundo em que vive, não considera sua história e suas condiçóes subjetivas, a sua idade e seus processos de desenvolvimento, suas motivaçóes e capacidades, fundamentando-se naquilo que ela é.

\section{CONSIDERAÇÕES FINAIS}

Quando a educação fracassa, milhares de crianças são privadas não apenas do acesso a determinados conteúdos da cultura e do conhecimento historicamente acumulado, mas de possibilidades mais amplas de desenvolvimento. Nesse contexto, a questấo não é somente quantos anos as crianças passarão na escola, mas em que escola elas passarão grande parte de sua infância. Isso porque o fato de estar na escola e ter acesso aos conteúdos escolares, por si só, não garante a formação da criança ou sua inclusão “na rede mais ampla possível da vida” (VIGOSTSKI, 2001, p. 351). 
Assim, embora o acesso à escola seja fundamental, ele é apenas o primeiro passo na garantia dos direitos das crianças à educação. Aportes financeiros suficientes e processos democráticos de discussão são condiçôes necessárias para que se possa garantir a qualidade da ampliação da obrigatoriedade escolar. Como nos lembram Kramer, Nunes e Corsino (2011, p. 75):

[a] educação é um campo de disputa. Educação infantil e ensino fundamental estáo colocados num patamar díspar na educação básica. Concorrem. A obrigatoriedade de frequência das crianças de 4 e 5 anos à escola pode levar à compreensão de que é aí que a educação básica começa, reiterando a antiga cisão entre creches e pré-escolas e trazendo de volta à cena o ideário de preparação para o ensino fundamental. Corre-se o risco de desvincular a educação infantil dos princípios formulados para a creche e a pré-escola e não se enfrenta a verticalidade do processo escolar, nem no que se refere à formulação das políticas nem no que diz respeito aos projetos curriculares. Acentua-se a fragmentação da educação básica sem atentar para as transições.

Nessa disputa, a criança é quem tem perdido sempre, vítima da fragmentação e das desarticulaçóes da educação básica. Retomando Vigotski (1995), compreendemos que não há linha reta no desenvolvimento da criança; na transição entre as diferentes idades, o que existe são "rupturas, substituição de funçôes, deslocamentos e luta de dois sistemas" (p. 309). Do mesmo modo, podemos ponderar que a passagem da educação infantil ao ensino fundamental também não constitui um caminho plano e direto, que pode ser percorrido com movimentos lineares e progressivos da criança. Serão necessários saltos para avançar e nenhuma atitude romântica que encarregue a própria criança, investida de um inerente poder criador, de realizar sozinha essa passagem poderá ajudá-la a saltar. Do mesmo modo, focalizar apenas as necessidades atuais da criança, sem considerar o percurso que se estende diante dela, pode resultar na criação de barreiras desnecessárias.

$\mathrm{Na}$ perspectiva que estamos assumindo, do ponto de vista do desenvolvimento, não há contradição entre atender às especificidades e necessidades das crianças pequenas e prepará-las para o ensino fun- 
damental. Preparação, nesse caso, afasta-se da ideia que discutimos, de antecipação da escolarização, e assume o sentido de ampliação gradativa da experiência cultural da criança e de organização de formas de existência social que possibilitem reestruturaçóes de sua consciência e transformações em suas relações com a realidade social.

Nesse sentido, introduzir mais cedo determinadas exigências relativas ao controle do comportamento da criança, a conhecimentos específicos e sistematizados sobre a escrita, a aritmética, a natureza e a sociedade, antes que tenham sido criadas, na relação entre criança e professor, as condiçôes para enfrentá-las, não torna a criança mais apta para encarar os desafios do ingresso no ensino fundamental; ao contrário, talvez apenas limite suas possibilidades de desenvolvimento e de aprendizagem e produza sentidos de fracasso.

Nesse contexto, a sistematização de conhecimentos pelas crianças não é o foco principal da educação infantil. Entendemos a sistematização de conhecimentos no sentido indicado por Vigotski (2010) de sistematização hierárquica de conceitos, própria da elaboração de conceitos científicos na escola. Para o autor, "o sistema e a tomada de consciência a ele vinculada não são trazidos de fora para o campo dos conceitos infantis", mas "pressupóem a existência de conceitos infantis bastantes ricos e maduros, sem os quais a criança não dispóe daquilo que deve tornar-se objeto de tomada de consciência e de sua sistematização" (VIGOTSKI, 2010, p. 293).

Nessa direção, a escola de educação infantil é espaço de ampliação da experiência cultural da criança e de elaboração de conhecimento sobre o vivido, em relaçóes cotidianas ricas e diversificadas; de intenso processo de desenvolvimento da linguagem, da imaginação e de formas culturais de percepção e de memória; de tornar a escrita e a aritmética relevantes à vida; de brincar e se relacionar.

A educação infantil é também o lugar do vínculo, do afeto, do descobrir-se e de ser respeitado como pessoa. Para isso, a criança precisa ser cuidada, alimentada, agasalhada, vestida, consolada. Antecipar a retirada do colo, da mamadeira, da fralda não a torna mais autônoma; ao contrário, talvez limite suas possibilidades de experimentar e conhecer a si e ao mundo.

Do ponto de vista do desenvolvimento, também não há contradições entre introduzir a criança no aprendizado sistemático da leitura e da 
aritmética, nos anos iniciais do ensino fundamental, e respeitar os modos de relação com o outro, com o mundo e com conhecimento que ela traz consigo da educação infantil. O vínculo, o afeto e o cuidado continuam sendo importantes. Brincar, movimentar-se, conversar, imaginar não a afastam da aprendizagem da leitura e da escrita. Ao contrário, o desenvolvimento da escrita sustenta-se em toda a história dos signos na criança — na história do gesto, da fala, da brincadeira e do desenho. Sustenta-se também na necessidade de ler e escrever, produzida por sua imersão em uma sociedade letrada e pelo trabalho da escola, iniciado já na educação infantil, de buscar tornar a escrita relevante à vida, colocando-a a serviço da organização da atividade das crianças, do registro de suas experiências, da memória, do acesso à informação relevante, do imaginário.

Os modos de agir e de pensar necessários ao aprendizado sistemático dos conhecimentos historicamente acumulados pela humanidade - tarefa dos ensinos fundamental e médio — não podem ser esperados como pré-requisitos no ingresso da criança no primeiro ano, mas terão que ser construídos nessa nova situação social em que ela está sendo inserida. No desenvolvimento, nada surge já formado. Novas formas de agir e de pensar vão se constituindo à medida que novas exigências são feitas à criança e, ao mesmo tempo, se criam as condiçóes para satisfazê-las.

Assim, na escola — seja de educação infantil ou de ensino fundamental - é preciso sempre lidar com a tensão dialética entre o que a criança é hoje e os seus processos de desenvolvimento em curso. Se isso não ocorre, particularmente no contexto de desigualdade social em que vivemos, estamos negando às crianças, especialmente às mais pobres, uma infância digna e rica em possibilidades de desenvolvimento.

\section{REFERÊNCIAS}

ALVES, T.; PINTO, J.M.R. Quem serão os potenciais ingressantes na educação básica brasileira com a ampliação da obrigatoriedade escolar? In GOUVEIA, A.B.; PINTO, J.M.R.; CORBUCCI, P.R. (org.). Federalismo e politicas educacionais na efetivação do direito à educação no Brasil. Brasília: Ipea, 2011.

ARELARO, L.R.G.; JACOMINI, M.A.; KLEIN, S.B. O ensino fundamental de nove anos e o direito à educação. Educação e Pesquisa, São Paulo, v. 37, n. 1, p. 35-51, jan./abr. 2011. 
BRASIL. Ministério da Educação. Conselho Nacional de Educação. Câmara de Educação Básica. Resoluçáo no 01, de 7 de abril de 1999. Institui as Diretrizes Curriculares Nacionais para a Educação Infantil. Diário Oficial da União, Brasília, DF, 13 abr. 1999. Seção 1, p. 18. Disponível em: <http://portal.mec. gov.br/cne/arquivos/pdf/CEB0199.pdf >. Acesso em: 07 dez. 2012.

Presidência da República. Casa Civil. Subchefia para Assuntos Jurídicos. Lei n. 11.274, de 6 de fevereiro de 2006. Altera a redação dos artigos 29, 30, 32 e 87 da Lei no 9.394 de 20 de dezembro de 1996, que estabelece as diretrizes e bases da educação nacional, dispondo sobre a duração de 9 (nove) anos para o ensino fundamental, com matrícula obrigatória a partir dos 6 (seis) anos de idade. Brasília, DF, 6 fev. 2006a. Disponível em: $\leq$ http://www. planalto.gov.br/ccivil_03/ato2004 2006/2006/lei/l11274.htm>. Acesso em: 2 fev. 2015.

. Presidência da República. Casa Civil. Subchefia para Assuntos Jurídicos. Lei n. 12.796, de 4 de abril de 2013. Altera a Lei no 9.394, de 20 de dezembro de 1996, que estabelece as diretrizes e bases da educaçáo nacional, para dispor sobre a formação dos profissionais da educação e dar outras providências. Brasília, DF, 4 abr. 2013. Disponível em: <http://www.planalto.gov.br/ccivil 03/ ato2011 2014/2013/lei/l12796.htm>. Acesso em: 2 fev. 2015.

Ministério da Educação. Secretaria de Educação Básica, Departamento de Políticas de Educação Infantil e Ensino Fundamental, Coordenação Geral do Ensino Fundamental. Ensino Fundamental de Nove Anos: orientaçôes para a inclusão da criança de seis anos de idade. + 1 ano é fundamental. Brasília: SEB/DPE/COEF, 2007. Disponível em: $\leq$ http:// portal.mec.gov.br/seb/arquivos/pdf/Ensfund/ensifund9anobasefinal.pdf>. Acesso em: 01 mar. 2014.

. Ministério da Educação. Secretaria de Educação Básica, Diretoria de Concepções e Orientações Curriculares para a Educação Básica, Coordenação Geral de ensino Fundamental. A criança de 6 anos, a linguagem escrita e o ensino fundamental de nove anos: orientaçóes para o trabalho com a linguagem escrita em turmas de crianças de seis anos de idade. Brasília: SEB, 2009a.

Ministério da Educação. Secretaria de Educação Básica, Diretoria de Concepçóes e Orientaçóes Curriculares para Educação Básica, Coordenação Geral do Ensino Fundamental. Ensino fundamental de nove anos: passo a passo do processo de implantação. 2a . ed. Brasília: Ministério da Educação, set. 2009b. Disponível em: <http://portal.mec.gov.br/dmdocuments/passo a passo versao atual_16_setembro.pdf $>$. Acesso em: 01. mar. 2014. 
BRASIL. Ministério da Educação. Secretaria de Educação Básica, Departamento de Políticas de Educação Infantil e Ensino Fundamental, Coordenação Geral do Ensino Fundamental. Ensino Fundamental de Nove Anos: orientaçóes gerais. Brasília: SEB/DPE/COEF, jul. 2004. Disponível em: $\leq$ http://portal.mec.gov. br/seb/arquivos/pdf/Ensfund/noveanorienger.pdf $>$. Acesso em: 01 mar. 2014.

Ministério da Educação. Secretaria de Educação Básica. Parâmetros Nacionais de Qualidade para a Educação Infantil. Brasília: SEB, $2006 \mathrm{~b}$.

- Ministério da Educação. Secretaria de Educação Básica. Politica Nacional de Educação Infantil: pelo direito das crianças de zero a seis anos à educação. Brasilia: SEB, 2005.

- Ministério da Educação. Secretaria de Educação Fundamental, Departamento de Política da Educaçáo Fundamental, Coordenação-Geral de Educação Infantil. Subsídios para credenciamento e funcionamento das instituiçôes de Educação Infantil. Brasília: MEC, 1998.

CAMPOS, M.M.; FÜLLGRAF, J.; WIGGERS, V. A qualidade da educação infantil brasileira: alguns resultados de pesquisa. Cadernos de Pesquisa, São Paulo, v. 36, n. 127, p. 87-128, jan./abr. 2006.

CHULEK, V. A educação infantil e o ensino fundamental de nove anos nas vozes de crianças e na organização do trabalho pedagógico de duas instituiçôes de Curitiba. 175 f. Dissertação (Mestrado em Educação) - Setor de Educação, Universidade Federal do Paraná, Curitiba, 2012.

CORREA, B.C. Educação infantil e ensino fundamental: desafios e desencontros na implantação de uma nova política. Educação e Pesquisa, São Paulo, v.37, n.1, p. 105-120, jan./abr. 2011a.

- Políticas de educação infantil no Brasil: ensaio sobre os desafios para a concretização de um direito. Jornal de Políticas Educacionais, Curitiba, n. 9, p. 20-29, jan./jun. 2011b.

ELKONIN, D.B. Epílogo. In: VYGOTSKI, L.S. Obras Escogidas. Psicología infantil. Tomo IV. Madri: Visor, 1996.

KOSTIUK, G.S. Alguns aspectos da relação recíproca entre educação e desenvolvimento da personalidade. In LEONTIEV, A.; LURIA, A.R.; VYGOTSKY, L. Psicologia e Pedagogia: bases psicológicas da aprendizagem e do desenvolvimento. São Paulo: Editora Moraes, 1991.

KRAMER, S.; NUNES, M.F.R.; CORSINO, P. Infância e crianças de 6 anos: desafios das transições na educação infantil e no ensino fundamental. Educação e Pesquisa, São Paulo, v. 37, n. 1, p. 69-85, jan./abr. 2011. 
LIMA, I.M.M. As experiências educacionais no contexto da transição da educação infantil para o ensino fundamental numa escola municipal de Fortaleza na perspectiva dos diversos segmentos da comunidade escolar. $134 \mathrm{f}$. Dissertação (Mestrado em Educação) - Faculdade de Educação, Universidade Federal do Ceará, Fortaleza, 2013.

MARCONDES, K.H.B. Continuidades e descontinuidades na transição da educação infantil para o ensino fundamental no contexto de nove anos. 373p. Tese (Doutorado em Educação Escolar) - Faculdade de Ciências e Letras, Universidade Estadual Paulista, Araraquara, 2012.

MARTINATI, A.Z. Faz de conta que eu cresci: o processo de transição da educação infantil para o ensino fundamental. 231p. Dissertação (Mestrado em Educação) - Centro de Ciências Humanas e Sociais Aplicadas, Pontifícia Universidade Católica de Campinas, Campinas, 2012.

MASCIOLI, S.A.Z. Cotidiano escolar e infância: interfaces da educaçáo infantil e do ensino fundamental nas vozes de seus protagonistas. $310 \mathrm{f}$. Tese (Doutorado em Educação Escolar) - Faculdade de Ciências e Letras, Universidade Estadual Paulista, Araraquara, 2012.

NEVES, V.F.A. Tensóes contemporâneas no processo de passagem da educação infantil para $o$ ensino fundamental: um estudo de caso. $271 \mathrm{f}$. Tese (Doutorado em Educaçăo) Faculdade de Educação, Universidade Federal de Minas Gerais, Belo Horizonte, 2010.

NOGUEIRA, G.M. A passagem da educação infantil para o $1^{\circ}$ Ano no contexto do Ensino Fundamental de nove anos: um estudo sobre alfabetização, letramento e cultura lúdica. 294 f. Tese (Doutorado em Educação) - Faculdade de Educação, Universidade Federal de Pelotas, Pelotas, 2011.

PINO, A. A criança e seu meio: contribuição de Vigotski ao desenvolvimento da criança e à sua educação. Psicologia USP, São Paulo, v. 21, n. 4, p. 741-756, out./dez. 2010.

RABINOVICH, S.B. A articulação da Educação Infantil com o Ensino Fundamental I: a voz das crianças, dos educadores e da família em relação ao ingresso no primeiro ano. 353 f. Tese (Doutorado em Educação) - Faculdade de Educação, Universidade de São Paulo, São Paulo, 2012.

ROSEMBERG, F. Educação infantil pós-Fundeb: avanços e tensões. Apresentado no Seminário Educar na Infância: perspectivas histórico-sociais. Curitiba, agosto 2007. Disponível em $\leq$ http://www.diversidadeducainfantil. org.br/biblioteca artigos.html>. Acesso em: 6 maio 2016.

VIEIRA, L.M.F. Obrigatoriedade escolar na educação infantil. Revista Retratos da Escola, Brasília, v. 5, n. 9, p. 245-262, jul./dez. 2011. 
VIGOTSKI, L.S. A construção do pensamento e da linguagem. São Paulo: Martins Fontes, 2010.

. Historia del desarrollo de las funciones psíquicas superiores. In Obras Escogidas. Problemas del desarrollo de la psique. Tomo III. Madri: Visor, 1995.

. Problemas de la psicología infantil. In Obras Escogidas. Psicología infantil. Tomo IV. Madri: Visor, 1996. . Psicologia da Arte. São Paulo: Martins Fontes, 1999. . Psicologia Pedagógica. São Paulo: Martins Fontes, 2001.

\section{NOTAS}

1. Essas tendências, que tiveram origem nas concepções de educação compensatória da década de 1970, desconsideram as especificidades da educação de crianças menores de seis anos e visam apenas a prepará-las para o ensino fundamental, por meio do treinamento de habilidades escolares e/ou da compensação de carências culturais, antecipando hábitos e comportamentos próprios de uma estruturação tradicional do ensino fundamental, bem como promovendo o exercício mecânico e repetitivo de tarefas escolares típicas desse modelo.

2. Ao discutir o problema da idade no desenvolvimento da criança, Vigotski (1996, p. 262) indica que cada idade possui uma estrutura "específica, única e irrepetível”. A ideia de reestruturação da consciência, nesse contexto, refere-se à transformação da estrutura da consciência em cada idade. Nas palavras do próprio teórico (VIGOTSKI, 1996, p. 262-263, tradução nossa), "[s]e analisamos a consciência da criança entendida como sua 'relação com o meio' (Marx) e a consideramos produto das mudanças físicas e sociais do indivíduo, como expressão integral das peculiaridades superiores e mais importantes da estrutura da personalidade, veremos que na transiçáo de uma idade a outra crescem e se desenvolvem não tanto os aspectos parciais, isolados da consciência ou algumas funçóes e modos de sua atividade, mas, em primeiro lugar, se modifica a estrutura geral da consciência que em cada idade se distingue por um sistema determinado de relaçóes e dependências entre seus aspectos isolados, entre as distintas formas de sua atividade”.

Recebido em 14 de janeiro de 2017.

Aprovado em 24 de junho de 2017. 